\title{
ISLAM E IDENTIDAD EN EL SENEGAL CONTEMPORÁNEO
}

\section{Islam and national identity in contemporary Senegal}

\author{
Juan Ignacio Castien Maestro* \\ * Universidad Complutense de Madrid \\ jicastien@hotmail.com
}

\section{Palabras clave \\ Islam \\ Senegal \\ Sufismo \\ Modernización \\ Identidad nacional}

\section{Keywords}

Islam

Senegal

Sufism

Modernization

National identity

\begin{abstract}
Resumen
En este artículo investigamos las relaciones entre la religión y la construcción de la identidad nacional. Para ello, combinamos diversas aportaciones de la antropología, la sociología y la historia. Se trata de una cuestión de una gran complejidad. En especial, supone adaptar un elemento tradicional, como lo es la religión, a los requerimientos de un proceso de modernización, caracterizado por el desarrollo de una mayor secularización e individuación. Nos centramos en el caso particular de Senegal, reinterpretando distintas aportaciones bibliográficas clásicas desde nuestro propio enfoque teórico y completándolo con materiales extraídos de nuestro propio trabajo de campo. En este país parece haberse dado una articulación bastante exitosa entre Islam y modernización, que lo vuelve muy interesante desde el punto de vista de las ciencias sociales. Exploramos los factores que parecen haber favorecido esta articulación, especialmente las características específicas del tipo de Islam predominante en el país, que son el resultado de un proceso histórico un tanto particular.
\end{abstract}

\section{Abstract}

This paper investigates the relationship between religion and the construction of national identity. To do this, we combine various contributions of anthropology, sociology and history. It is a matter of great complexity. In particular, it involves adapting a traditional element, as is religion, to the requirements of a modernization process, characterized by the development of greater secularization and individualization. We focus on the particular case of Senegal, reinterpreting classic literature different contributions from our own theoretical approach and supplementing it with materials extracted from our own fieldwork. In this country seems a fairly successful articulation between Islam and modernization, which makes it very interesting from the point of view of the social sciences has been given. We explore the factors that seem to have favored this joint, especially the specific characteristics of the type of predominant Islam in the country, which are the result of a particular historical process somewhat.

Castien Maestro, J.I. (2016). Islam e identidad en el Senegal contemporáneo. Papeles del CEIC, vol. 2016/2, papel 157, CEIC (Centro de Estudios sobre la Identidad Colectiva), Universidad del País Vasco, http://dx.doi.org/10.1387/pceic.16144 


\section{NACIÓN Y RELIGIÓN EN EL MUNDO MUSULMÁN}

Las relaciones entre identidad nacional y religión constituyen un tema ya clásico en el campo de las ciencias sociales ${ }^{1}$. Son unas relaciones marcadas a un mismo tiempo por la continuidad y la ruptura. Es frecuente que la religión, a través de la identidad colectiva que suele derivarse de ella, suministre un componente fundamental de esta identidad nacional. Puede hacerlo también aportando una serie de modelos culturales, que, tras ser relativamente secularizados, es decir, desligados de su matriz religiosa originaria, ayudarán a organizar la nueva identidad y contribuirán a una reconstrucción de la propia tradición cultural y de la propia historia colectiva acordes con ella (Hastings, 2002). Pero estas continuidades quedan contrarrestadas por todo un conjunto de rupturas. No en vano, las sociedades modernas han experimentado, si bien con una intensidad variable, un evidente proceso de secularización, como resultado de una creciente complejidad estructural, difícil de gestionar sobre la base de ninguna cosmovisión de carácter religioso. En virtud de este proceso, las nuevas identidades colectivas, entre ellas las nacionales, adquieren una autonomía con respecto a la religión que impide reducirlas a meros epifenómenos de la

\footnotetext{
${ }^{1}$ Partimos de una definición mínima de la religión, substantiva y no funcional, como un tipo particular de ideología organizado en torno a un conjunto de creencias referidas a entidades supra-empíricas. A estas creencias se subordinan, casi siempre, una serie de principios normativos y de identidad, conectados, a su vez, con toda una serie de prácticas e instituciones. La identidad religiosa es aquella identidad social definida por la adhesión una determinada religión. Puede presentar luego diversas modalidades particulares, en función de la versión específicamente profesada de esa religión. Entendemos por secularización la autonomización de determinadas esferas de actividad con respecto a la religión, así como la autonomización también de ciertos elementos -como creencias, normas, identidades, símbolos o valores- con respecto a aquella religión en donde estaban originariamente integrados. Esta secularización no implica que la religión no pueda conservar su influencia sobre otras facetas de la existencia, en especial, invistiendo a la misma de un sentido teleológico global (Castien, 2008). La identidad nacional se define por la pertenencia a una nación. Las naciones suelen poseer una "cultura nacional", más o menos rica y compleja, algunos de cuyos elementos funcionan como marcadores de identidad, y suelen haber sido recreados precisamente con esta finalidad. Una nación se diferencia de otras colectividades culturalmente definidas, como las "etnias" y las "nacionalidades", que también recrean sus propios marcadores de identidad, por la reivindicación por parte de sus integrantes de una soberanía política, incluso aunque la misma no se plasme forzosamente en un Estado independiente, ya exista esta soberanía en el presente o sólo como un proyecto para el futuro (Gellner, 1989). Por supuesto, la nación y el Estado-nación son construcciones históricas recientes ligadas al proceso de modernización, lo que las diferencia de otras más tradicionales como la religión y la identidad religiosa.
} 
misma. Responden ahora a una dinámica en gran medida propia, en lo que atañe a las elaboraciones doctrinales y a las estructuras organizativas sobre las que reposan.

Asimismo, al igual que las nuevas identidades nacionales pueden verse reforzadas tan a menudo por su vinculación con una religión y una identidad religiosa previamente existentes, también ocurre a veces lo contrario. Los límites de la comunidad religiosa y los de la identidad nacional quizá no coincidan. Los adherentes a una misma fe pertenecerán entonces a naciones enfrentadas, de manera que los intereses de la comunidad religiosa y los de la comunidad nacional podrán resultar divergentes. Del mismo modo, la comunidad nacional puede hallarse internamente dividida entre distintas comunidades religiosas. A no ser que se opte en ese caso por eliminar o marginar a una parte de los connacionales, será preciso establecer un vínculo de identidad capaz de trascender estas diferencias. Ello resulta especialmente necesario en el mundo moderno, un mundo de Estados mucho más presentes en la vida cotidiana de las personas y de sociedades mucho más integradas en todos los aspectos, cuyos miembros requieren de unas identidades comunes que faciliten su interacción cotidiana (Gellner, 1989). De ahí que la cuestión de la compatibilidad entre las identidades religiosas y las nacionales ostente una relevancia radical.

Por último, las nuevas identidades nacionales han de ajustarse, en alguna medida, a las exigencias de la vida social moderna, si es que han de ser viables. Deben resultar mínimamente compatibles con el progreso tecnológico y con el desarrollo de instituciones estables y bien organizadas, así como con un estilo de vida acorde con ambos. De este modo, siguiendo aquí a Clifford Geertz (1987: 210-214), requieren de un componente más epocalista, junto con ese otro más esencialista, consistente en la preservación de algún tipo de vinculación con las identidades y tradiciones culturales previas a la constitución de la nueva nación. En términos generales, los elementos tomados de la religión quedarían englobados dentro de este último componente esencialista. El reto estribaría entonces en cómo compaginar este recurso parcial a lo tradicional con la compatibilidad con el mundo moderno propia del elemento epocalista. Hacerlo no siempre va a resultar sencillo, no sólo por las razones ya mencionadas, sino también por la presencia en el seno de muchas religiones de unos códigos normativos atribuidos a 
algún mandato sobrenatural, lo que dificulta su adaptación a unas nuevas circunstancias históricas. Se hace complicado, en particular, conciliar la obediencia a estos códigos religiosos con esa mayor autonomía individual que constituye uno de los aspectos fundamentales de la existencia moderna (Elias, 1990; Giddens, 1995). Por tanto, mientras que, desde el punto de vista epocalista, la nueva identidad nacional ha de resultar compatible con la libertad de crítica y de elección, ambas pueden entrar en contradicción, a su vez, con esa obligatoriedad de creer y de obedecer tan habituales en las religiones tradicionales. Combinar las exigencias de autonomía individual e integración colectiva no es tarea sencilla.

En contextos de modernización acelerada y autoritaria ha sido esta última la que ha tendido ser priorizada, sacrificándose las libertades a la construcción nacional, al promoverse una homogeneidad colectiva basada en lo fundamental en el componente esencialista. El resultado ha sido el establecimiento de una suerte de nueva solidaridad mecánica, en el sentido durkheimiano del término. La operación ha tenido muchas veces éxito a corto plazo, pero ha acabado suscitando más adelante la rebeldía de muchos, descontentos con las imposiciones sufridas. No obstante, alli en donde se ha optado por otorgar un mayor peso al componente epocalista también han surgido problemas semejantes, sobre todo cuando lo moderno ha sido identificado sin más con lo occidental. El ataque contra las tradiciones más arraigadas ha requerido entonces de un intenso autoritarismo y de una fuerte represión de la disidencia, tan disfuncionales ambos para una sociedad que se diversifica y en donde se hace preciso preservar y aprovechar la heterogeneidad de los individuos y de los colectivos que la componen. Una y otra vez, el gran problema ha sido el de cómo lograr encajar dentro del gran molde colectivo propuesto a gentes cuyas identidades específicas no siempre resultaban compatibles con aquél, ya fuese por tratarse de unas identidades previas y arraigadas, "primordiales" (Geertz, 1987: 219-261), o por ser el resultado de unos desarrollos más recientes, pero en direcciones distintas.

El mundo musulmán ha constituido a lo largo del último siglo un inmenso laboratorio para este género de experiencias. La importancia de la religión islámica como eje vertebrador de una gran parte de su cultura resulta patente en su caso, como lo es también la de la identidad musulmana como componente clave de la identidad colectiva. Aquí 
radica su relevancia con respecto a los distintos procesos de construcción nacional que han tenido lugar en esta región del mundo. En general, el componente esencialista de la cultura y de la identidad nacionales ha tomado mucho de esta religión. El Islam ha operado, así, como un eficaz instrumento de integración social, al subordinarse las distintas pertenencias tribales, étnicas o regionales a una común identidad religiosa. Desde este punto de vista, el recurso al Islam ha desempeñado un claro papel modernizador, incluso a pesar de los conflictos ocasionados con quienes abogaban por otras variantes de esta religión o con las minorías más secularistas. Lo mismo ha ocurrido también con su empleo como signo privilegiado de diferenciación frente a un Occidente con el que se continúan manteniendo todavía relaciones de orden neocolonial. En contrapartida, la promoción de la identidad musulmana ha implicado casi siempre, en alguna medida, la del derecho islámico, cuya compatibilidad con una vida secularizada y con la autonomía individual se muestra a veces problemática (Charfi, 2001: 73120).

Así ha sucedido, a pesar, incluso, de la introducción de interpretaciones más o menos modernistas del Islam y del hecho, bien constatado, de que la reivindicación de la identidad islámica, entendida incluso de un modo conservador, y de un estilo de vida en concordancia con ella, puedan operar en ciertos casos como un medio de afirmación individual y colectiva frente a las autoridades tradicionales (Burgat, 1996: 249-257), así como de construcción de una identidad personal más compleja, en parte, gracias al auto-conocimiento propiciado por el esfuerzo por ajustarse a unos mandamientos muy estrictos (Augis, 2008; Coulon, 2009: 64-65). En suma, las reinterpretaciones epocalistas del propio Islam han mostrado hasta el momento ciertas limitaciones. Del otro lado, la opción más decididamente epocalista por el laicismo a ultranza, y por un occidentalismo mimético, practicada sobre todo en la Turquía kemalista, ha propiciado una marcada escisión entre las elites y el conjunto de la población, que sólo ha podido sostenerse, por un tiempo, con ayuda de una dura represión política (Zarcone, 2005: 113-194).

Frente a este abanico de aparentes antinomias irresolubles, puede revestir un claro interés el examen de un caso relativamente menos conocido como lo es el de Senegal. Allí la confesión musulmana de la inmensa mayoría de la población ha podido conciliarse con la construcción de un Estado laico y progresivamente democrático 
(Loimeier, 2008; Ndao, 2003; Seck, 2005). Estos logros han sido favorecidos, en nuestra opinión, por algunas especificidades del tipo de Islam predominante hoy en día en el país. En este artículo pretendemos localizar algunos de los rasgos distintivos de este "Islam senegalés" que parecen volverlo especialmente compatible con los requisitos básicos de una sociedad moderna apuntados más arriba, tales como una identidad nacional mayoritariamente asumida, una relativa secularización de diversas facetas de la vida social y el reconocimiento de una cierta autonomía individual con respecto a las normas sociales imperantes. Vamos asimismo a tratar de explicar el origen de tales rasgos particulares a partir de un análisis de su desarrollo histórico de carácter multicausal, en el curso del cual iremos añadiendo una serie de hipótesis complementarias.

Con este fin, vamos a servirnos de diversas fuentes bibliográficas y, en menor medida, de algunos datos obtenidos en nuestro trabajo de campo entre la población senegalesa en España desde 2012 y en las ciudades de Dakar, Saint-Louis Touba y Kaolack en el verano de 2014. Confrontaremos estos materiales con las problemáticas y con las categorias analíticas introducidas más arriba, lo que nos ayudará a reinterpretar parcialmente algunos hechos conocidos, así como a otorgar una mayor precisión a nuestros esquemas de partida. Esperamos que estos análisis nos ayuden a entender mejor no sólo la ya tantas veces apuntada adaptabilidad del Islam a distintos contextos particulares, sino también las formas específicas en que tal adaptación puede producirse en un caso determinado.

\section{ESPECIFICIDADES REALES Y SUPUESTAS DEL ISLAM SENEGALÉS}

El Islam llegó al actual territorio senegalés desde lo que hoy en día es Mauritania. Pero esta última, a pesar del notable nivel alcanzado por sus especialistas religiosos, era tributaria, ante todo, de los grandes desarrollos que estaba experimentando Marruecos en campos como la mística sufí, el derecho islámico y la teología. De ahí que el Islam senegalés haya reproducido los rasgos básicos del Islam marroquí, tal y como éstos quedaron conformados durante la Edad Media (Geertz, 1971: 5-13). Se trata, por ello, de un Islam sunní y malekí con una fuerte presencia del sufismo, tanto en sus formas más sofisticadas, como en las más populares. La principal diferencia entre ambos paises estriba en que en Marruecos el sufismo ha perdido hoy mucha de su antigua influencia, 
ha sido el blanco de críticas acerbas por parte tanto de los modernistas como de los salafistas y la afiliación actual a las cofradías es francamente minoritaria (El Ayadi et al., 2007: 58-59), mientras que en Senegal este mismo sufismo ha experimentado, por el contrario, un desarrollo auténticamente espectacular, alcanzando una influencia inmensa sobre la vida cotidiana de la gente, pero también sobre la actividad política y económica (Copans, 1989; Coulon, 1981; Diop, 1981: 297-319; Magassouba, 1985; Seck, 2010; Villalón, 1995).

Esta notable influencia de las cofradías sufies no constituye, ciertamente, un rasgo privativo de Senegal. Fenómenos parecidos se observan por todo el mundo musulmán. Pero no parece que en ningún lugar hayan alcanzado unas dimensiones equivalentes. Los intentos de explicar la especificidad senegalesa han discurrido, sin embargo, por distintos derroteros. Uno de ellos, muy transitado, atribuye estas peculiaridades a la impronta de las tradiciones preislámicas. El "animismo" previamente existente habría favorecido, así, la asimilación de aquellos elementos del Islam más acordes consigo mismo, como sería el caso precisamente de un cierto tipo de sufismo, caracterizado por el culto a los santones y la ubicuidad de los hechos milagrosos. El Islam senegalés, sería, de este modo, un ejemplo paradigmático del llamado "Islam negro", un Islam híbrido y sincrético, muy distinto del Islam imperante en el Magreb, presuntamente más "ortodoxo". Este "Islam negro" se distinguiría, asimismo, por una notoria indiferencia hacia las cuestiones doctrinales y jurídicas. Su atención recaería más bien en la emoción asociada a ciertos rituales, como los oficiados precisamente en el marco de las cofradías, herederas en parte de las antiguas sociedades iniciáticas.

Sin embargo, este concepto de "Islam negro" resulta harto problemático. Fue acuñado en el marco del colonialismo francés $y$, junto a una visión primitivista del negro-africano, como alguien despreocupado por lo doctrinal e incapaz, por ello, de aprehender el Islam en toda su complejidad, respondía también a una clara intencionalidad política. Tomando al Islam como el gran adversario histórico de los pueblos europeos y, en consecuencia, de su empresa colonial, se trataba de resaltar la idiosincrasia de los musulmanes del África subsahariana a fin de sustraerlos al influjo de los árabes, tenidos por más "ortodoxos" y, por tanto, más peligrosos, lo que facilitaría su anuencia hacia la nueva dominación (Coulon, 1981: 5-8; Seesemann, 
2011: 11-15; Ware, 2008: 30). Las independencias africanas no han supuesto el final de este planteamiento, que, en cambio, ha adquirido nuevas virtualidades. El predomino de este peculiar Islam, se dice así, estaría propiciando actualmente una llamativa renuencia de la población con respecto a las propuestas doctrinarias y maximalistas del islamismo y del salafismo, lo cual favorecería indirectamente el desarrollo democrático.

Parece dudoso, sin embargo, que, en un mundo culturalmente tan heterogéneo como el negro-africano, pueda existir un Islam tan uniforme. Tampoco tiene en cuenta este planteamiento los profundos cambios experimentados por el Islam del Sahel a lo largo de su historia. Ciertamente, durante siglos ha tenido lugar un complejo proceso de hibridación entre esta religión y las diversas tradiciones locales. Esta constatación autoriza, en nuestra opinión, el empleo, si bien con suma prudencia, de una expresión como la de "Islam negro", aunque parece preferible la más británica de "Islam híbrido" o "mestizo". Semejante Islam se caracterizaría, en efecto, por un acentuado sincretismo con las religiones tradicionales africanas. Este sincretismo no afectaría únicamente a las creencias y rituales, sino también al plano normativo, de forma que en su caso el derecho islámico clásico sólo se aplicaría de una manera muy parcial. Pero tampoco debemos olvidar que este sincretismo se ha dado también históricamente entre la mayoría de las poblaciones musulmanas, incluidas las de la propia Península Arábiga (Vassiliev, 2000: 70-76). No tiene nada de específicamente negroafricano.

Asimismo, entre los propios musulmanes negro-africanos han existido desde la Edad Media ciertos núcleos opuestos a este eclecticismo religioso y partidarios de la depuración del Islam local de cualquier adherencia "pagana", así como de una aplicación mucho más rigurosa de la legislación musulmana. Este rigorismo ha experimentado una notoria expansión desde principios del siglo XIX, en gran medida por efecto de una sucesión de yihad que instauraron a lo largo del Sahel una serie de Estados teocráticos, cuyo proyecto ideológico estribaba precisamente en la imposición del "verdadero Islam" en la región, mediante la reeducación de sus propias poblaciones y el derrocamiento de los distintos gobernantes impíos o tibios (Robinson, 1988: 51-83). Conforme este rigorismo ha venido propagándose desde entonces, el viejo Islam híbrido ha ido retrocediendo, al igual que en otros muchos 
lugares. De ahí que, el Islam del Sahel, y más en concreto el de Senegal, exhiba a día de hoy todo un conjunto de homologías básicas con el existente en el resto del mundo musulmán.

Senegal cuenta actualmente con una notable tradición de erudición islámica en todos los campos, desde el derecho hasta la mística, algunas de cuyas figuras han alcanzado una amplia proyección internacional (Seesemann, 2011). Las célebres cofradías senegalesas no dejan de ser secciones de otras de origen foráneo, como sucede con la Qadiriya y la Tiyaniya, o, a lo sumo, desarrollos autónomos a partir del tronco común del sufismo, como lo es la Muridiya. Por último, el afán por imponer una normativa y un estilo de vida en línea con el derecho islámico tradicional se halla muy presente en su caso, como lo está también el proyecto de convertir al Islam en religión de Estado y acabar con el actual sistema laico. Anima además a una gran parte de los líderes de las cofradías, quienes, como ha sido habitual en todas partes a lo largo de la historia, compaginan sin mayores problemas el sufismo y el derecho islámico, incluso el más rigorista (Coulon, 1981: 228-230 y 271-279; Magassouba, 1985: 101-145; Seck, 2010: 109-120). Desde hace décadas, los movimientos islamistas y salafistas actúan además en el país y sus críticas contra las "desviaciones" prácticas y doctrinales de las cofradías se han ganado a una significativa minoría de la población (Costa, 2009; Seck, 2010: 149-173). Todos estos hechos nos muestran que la situación en Senegal no difiere en modos absolutos de la existente actualmente en la mayoría de los paises musulmanes. La diferencia reside sólo en el peso relativo del que disfrutan en cada caso las distintas corrientes ideológicas.

La realidad es, pues, heterogénea y cambiante. Se resiste a cualquier explicación simplista basada en las presuntas esencias del Islam local. La herencia del antiguo Islam híbrido es importante, pero es sólo un elemento más dentro de una ecuación más amplia. Es preciso, por ello, desarrollar un marco explicativo más complejo, que atienda a una multiplicidad de factores y tenga presente en todo momento su dimensión histórica. Sólo entonces podremos empezar a entender mejor las especificidades reales del Islam de Senegal. 


\section{El desarRollo del ISLAM en EL SENEGAL Poscolonial}

El Islam penetró relativamente temprano en Senegal. Parece que la islamización del actual Futa Toro, en el norte, se había iniciado ya en el siglo XI (Ware, 2008: 22). En los siglos siguientes esta religión fue propagándose hacia el sur, hacia los distintos reinos sonninké, wolof, serer y mandinga. Los promotores de esta expansión fueron especialistas religiosos, progresivamente encuadrados dentro de cofradías sufíes, a los que con mucha frecuencia se atribuían poderes milagrosos. La literatura colonial europea les adjudicó el nombre de marabut, equivalente al español morabito, y el término se ha vuelto con el tiempo de uso prácticamente universal. En una primera fase, el Islam profesado por la mayoría de la población mostró una clara hibridación con las religiones tradicionales locales, lo que resulta explicable por la condición fuertemente minoritaria de estos marabut, su ausencia de medios coercitivos y la dificultad de erradicar unas tradiciones religiosas que organizaban una gran parte de la vida social. Sin embargo, los marabut pudieron invertir su debilidad inicial, aprovechando las oportunidades que les brindaban las sociedades en donde operaban. Eran éstas unas sociedades aldeanas dedicadas a la agricultura de subsistencia. En ocasiones, una aristocracia guerrera emergía de entre la población campesina, asentando su poder sobre los tributos extraídos a los aldeanos, el trabajo de sus esclavos y, cada vez en mayor medida, el comercio con los arabo-bereberes del norte y los europeos de la costa. En este comercio los esclavos eran la principal mercancía exportada, trocada fundamentalmente por objetos de lujo, caballos y armas de fuego. El afán por adquirir estos bienes llevaba a los aristócratas a asolar los territorios de sus vecinos, en busca de gentes a quienes esclavizar, e incluso, a veces, a apresar también a sus propios súbditos (Barry, 1988: 26-70 y 121-42; Bathily, 1989: 167-236 y 254-305; Coulon, 1981: 55-60; Diop, 1981: 115-204).

Los marabut mantuvieron unas relaciones harto complejas con las aristocracias tradicionales. Podian entablar con ellas una suerte de alianza táctica, combatiendo en sus guerras, predicando a su favor y poniendo a su servicio sus dotes taumatúrgicas y sus habilidades para la escritura, tan importantes para el funcionamiento de una administración incipiente. Al mismo tiempo, se agrupaban en comunidades semi-autónomas, en lo político y en lo económico, que brindaban cobijo a los campesinos que huían de la opresión 
aristocrática, e iban desarrollando extensas redes de apoyo mutuo (Babou, 2007: 22-32), asentadas sobre una amplia cadena de escuelas coránicas (Ware, 2008: 22-26). Esta conformación de un auténtico partido marabútico entrañaba a más largo plazo un serio desafío para el orden tradicional. Los marabut abogaban por una escrupulosa obediencia a la Sharia, entendida ésta de un modo muy tradicionalista, en oposición al Islam híbrido o al simple "paganismo" de los aristócratas. Bajo los gobiernos genuinamente islámicos que habrían de instaurarse entonces, terminarian lo abusos contra los campesinos y se decretaría un sistema de tributación mucho más moderado, acorde con el derecho islámico. También se acabaría con la ilícita esclavización de musulmanes, sobre todo cuando éstos eran luego vendidos a los infieles europeos.

El nuevo sistema habría de establecerse mediante la conversión de las aristocracias o mediante su derrocamiento y su reemplazo por el gobierno directo de los propios marabut (Bathily, 1989: 209-212; Coulon, 1981: 60-63; Diop, 1981: 220-245). Los orígenes de este proyecto teocrático nos remiten hasta la actual Mauritania. Allí, a mediados del siglo XVII, una serie de líderes musulmanes trataron ya de establecer un régimen de este tipo, encabezando una amplia coalición tribal en contra del poder de unas aristocracias más secularizadas en su modo de vida. El movimiento se extendió al sur del río Senegal antes de ser finalmente aplastado por una coalición de aristócratas negro-africanos, tribus beduinas y comerciantes europeos. Pero aunque derrotado, su recuerdo perduró como un modelo a imitar (Barry, 1988: 88-95; Robinson, 1988: 54-55). De este modo, la posterior "revolución marabútica" en tierras senegalesas tuvo un primer origen magrebi, en oposición a cualquier presunta idiosincrasia irreductible del "Islam negro".

En pocos años los marabut empezaron a aventurarse a tomar directamente el poder. Surgieron, así, a lo largo del siglo XVIII una serie de pequeños Estados teocráticos en la región. Fue el punto de partida de la ya mencionada yihad saheliana. Este auge del marabutismo resultó favorecido por el deterioro en la posición de las aristocracias guerreras, como consecuencia, ante todo, de la decadencia y posterior desaparición de la trata de esclavos hacia América durante la primera mitad del siglo XIX (Barry, 1988: 190-208). La crisis del viejo sistema se vio agravada por el inicio de la conquista colonial pocas décadas después. Esta conquista discurrió a través de una serie de campañas 
militares, de resultas de las cuales las antiguas aristocracias quedaron en gran parte liquidadas bajo los golpes simultáneos de los franceses y de los marabut. Estos últimos se beneficiaron de manera inmediata del cambio de escenario. De una parte, el hundimiento de los regímenes tradicionales dejó un vacío de poder que ellos se aprestaron a ocupar, estableciendo nuevos gobiernos teocráticos allí donde les fue posible. De la otra, pudieron ahora ampliar el alcance de su yihad, dirigiéndola no solamente ya contra los paganos y los malos musulmanes, sino también contra los invasores cristianos. Su lucha contra éstos les otorgó una gran popularidad y les permitió profundizar en la islamización de la población. Por supuesto, en el curso de pocas décadas, los distintos Estados teocráticos que fundaron sucumbieron ante la abrumadora superioridad militar de los colonizadores (Barry, 1988: 305-331; Coulon, 1981:37-53 y 63-67). Así, la misma irrupción colonial que, en un primer momento, propició el desarrollo de estos Estados acabó ocasionando luego su desaparición.

\section{DeL COLONiALISMO A LA INDEPENDENCIA}

Pero el fin de estos Estados no supuso, en modo alguno, el de los propios marabut. Éstos, por el contrario, acabaron convertidos en los grandes beneficiarios de la colonización. Si así ocurrió, fue sobre todo gracias a la extraordinaria versatilidad de la que hicieron gala. Tras admitir su imposibilidad de resistir al colonialismo con las armas, concentraron sus esfuerzos en la mística y la erudición, pero también en la organización de la vida social y económica de sus adeptos. Con ello, no inventaron propiamente nada nuevo. Ya se habían dado experiencias similares sobre todo en el Magreb, su gran fuente de inspiración. Allí ciertos místicos sufies habian establecido plantaciones agrícolas y redes comerciales, haciendo trabajar a sus discipulos en el campo y convirtiendo las distintas secciones locales de sus cofradias en otras tantas agencias dedicadas al tráfico mercantil (Pascon, 1984; Stewart, 1973: 209-222). Los marabut senegaleses partieron de esta experiencia y la desarrollaron aún en mayor grado, consagrándose sobre todo al desarrollo de los cultivos comerciales, a los que más tarde se añadiría una intensa actividad mercantil e inmobiliaria (Coulon, 1981: 165-170; Copans, 1989: 157-172).

Este rol económico se insertó dentro de otro más amplio de dinamización social. Los marabuts creaban redes de solidaridad, 
socorrían a los más necesitados, ejercían un liderazgo moral, arbitraban en las disputas y proporcionaban consuelo frente a las adversidades cotidianas. Actuaban también como mediadores entre la población y las autoridades coloniales. Todo ello propició una progresiva acomodación mutua entre estas últimas y los marabut (Coulon, 1981: 158-193; Robinson, 2000). Desde la perspectiva marabútica, se trataba de acatar la dominación francesa como una prueba a la que Dios sometía a sus fieles y que algún día habría de terminar, aprovechando entre tanto sus aspectos positivos. Se desarrolló, así, una perspectiva más pragmática, en sustitución del maximalismo de la época de las yihad (Robinson, 2000). Este pragmatismo, esta disposición a acatar un gobierno alejado del ideal islámico, desentendiéndose parcialmente de la esfera política y concentrándose en la regulación de la moral cotidiana de los fieles (Charfi, 2001: 204), no dejaba de constituir una adaptación a un nuevo contexto histórico de una postura tradicionalmente mayoritaria entre los ulemas sunnies (Carré, 1996: 63-74).

Esta opción suponía, al tiempo, aprovechar el prestigio y la capacidad organizativa acumulados durante las guerras pasadas en un escenario de paz, con nuevos medios de transporte, que facilitaban la actividad misional, una población parcialmente desencuadrada, por la desaparición de los gobiernos aristocráticos y las migraciones internas, y una mayor receptividad hacia el Islam por parte de los "animistas", ahora que el mismo no venía ya asociado a la violencia (Searing, 2008: 99-101). Las redes sufíes pudieron, de este modo, reemplazar las estructuras sociales y los sistemas culturales propios del período aristocrático, por otros más adaptados al nuevo contexto de gobierno colonial, desarrollo capitalista, crecimiento demográfico y urbanización. Pero las antiguas formas socio-culturales fueron parcialmente integradas en el nuevo sistema, sin que se produjera una ruptura absoluta con ellas. Así, los marabuts se convirtieron en los receptores de las ofrendas de amplias masas de fieles, integradas por campesinos, artesanos y antiguos esclavos, un poco a la manera de la antigua aristocracia. En cuanto a esta última, resultó parcialmente absorbida dentro de las nuevas redes sociales, a través sobre todo de intercambios matrimoniales con las grandes familias sufies (Diop, 1981: 287-296 y 300-310).

El nuevo Senegal independiente ha prolongado en buena medida el modelo establecido durante el período colonial, sólo que las autoridades francesas han sido reemplazadas por un Estado laico, dirigido por unas 
élites un tanto occidentalizadas. Sin embargo, esta laicidad del Estado ha tenido que acomodarse a una sociedad mucho menos secularizada. No en vano, la debilidad de un Estado en construcción ha exigido seguir recurriendo al rol mediador y organizador de las cofradías. Asimismo, el carácter progresivamente democrático de este Estado, ha obligado a tomar en cuenta los puntos de vista de la mayoría de la población. En particular, la autonomía económica de los marabut y sus múltiples funciones sociales les han convertido en el eje de una peculiar sociedad civil, capaz de actuar como un eficaz contrapeso al poder estatal, frenando su posible hipertrofia frente a una sociedad civil poco desarrollada, tan común actualmente en África y en el mundo islámico (Ayubi, 1998: 270-287; Villalón, 1995: 258-265).

En un contexto de procesos electorales crecientemente competitivos, las distintas fuerzas en liza han recurrido además de un modo reiterado al apoyo de los marabut. En este aspecto, la situación de Senegal no resulta tan diferente de la de ciertos países de tradición cristiana, como Polonia, Irlanda y los propios Estados Unidos, y difiere marcadamente del viejo proyecto turco de laicidad autoritaria y de persecución de las cofradías sufies. Al tiempo las divisiones entre las distintas cofradías y entre las grandes familias marabúticas ha dificultado la constitución de un frente unido en favor de una mayor islamización del Estado y de la sociedad. Se ha recreado, por el contrario, una serie de alianzas coyunturales entre distintos marabut, políticos y hombres de negocios, en el que todas las partes implicadas salen beneficiadas, en términos materiales o de legitimidad. Se trata de una suerte de clientelismo fluido y multidireccional. Los intercambios de servicios recrean relaciones de dependencia reciproca, en donde las correlaciones de fuerza entre los participantes resultan muy inestables. De igual manera, las luchas intestinas dentro de cada uno de estos ámbitos conducen al establecimiento de coaliciones trasversales con los integrantes de los otros dos, y en competencia con otras coaliciones similares (Coulon, 1981: 208-264; Magassouba, 1985: 83-121; Villalón, 1995).

Todo este complejo intercambio de servicios permite a las redes sufíes seguir satisfaciendo las múltiples demandas de sus adherentes. Aquí reside una de las razones fundamentales de la debilidad mostrada hasta el momento por los islamistas, en la línea de los Hermanos Musulmanes, y por los salafistas, cuya labor social, que tanto facilita su proselitismo en otros países, ya es ampliamente realizada aquí desde las propias 
cofradías. Asimismo, este escenario de mutuas acomodaciones y de fuerte fraccionalismo dificulta el desarrollo de un proyecto de Islam político, basado necesariamente en una oposición mucho más marcada a las autoridades y al modelo social imperante. Ello no significa que la exigencia de una mayor islamización de la sociedad y del Estado no sea formulada por ciertos sectores sociales, como ya señalamos. Lo que ocurre es que esta demanda es recogida, y encauzada, por una parte de los propios marabut (Coulon, 1981: 271-280; Magassouba, 1985: 123-145; Seck, 2010: 68-78). De hecho, las cofradías hacen gala a menudo de un cierto eclecticismo ideológico con efectos claramente inclusivos. Según el momento, abogan resueltamente por esta islamización y por una vuelta al rigorismo en las costumbres, o juegan la carta opuesta, defendiendo la unidad de todos los senegaleses con independencia de sus creencias, la convivencia interreligiosa y la profundización de la democracia (Villalón, 1995: 1-2). Mediante estas oscilaciones tácticas, consiguen mantener en torno suyo una clientela muy diversa y ejercer de árbitros en el interior de la misma.

El sistema puede ciertamente ser criticado desde diversos puntos de vista, tanto por las desigualdades y la explotación que comporta con frecuencia (Copans, 1989), como en razón de la contradicción entre la condición de ciudadano libre y la del discípulo obediente a los mandatos de su sheij, si bien se constata desde los años ochenta una progresiva "desobediencia" con respecto a las orientaciones electorales de los marabut, junto con un rechazo a sus "intromisiones" en las luchas entre los partidos (Loimeier, 2008: 245-247; Magassouba, 1985:138-144; Seck, 2010: 88-90), así como una renuencia entre los propios marabut a brindar consignas políticas, ante el temor de que éstas no sean acatadas por sus discípulos (Villalón, 1995: 198-199). Así, como en tantos otros lugares, en el proceso de modernización senegalés habría primado también inicialmente la integración colectiva sobre la autonomía individual, por más que esta última se vaya afirmando también. Pero, en conjunto, estamos ante un sistema muy flexible, que ha ayudado a evitar las conflagraciones civiles que han afectado a otros países de su entorno, sobre todo al insertar a los diferentes actores políticos dentro de unas redes muy amplias, en donde han de contemporizar con muchos agentes diferentes (Villalón, 1995).

En nuestra opinión, esta situación ha fomentado una orientación pragmática general que se ha articulado con una particular concepción 
de la identidad musulmana, la cual se haya ligada, a su vez, a una específica manera de entender la identidad senegalesa. Es la hipótesis general que vamos a intentar argumentar a continuación y a la que iremos completando con otras de menor alcance, a la espera de poder contrastarla mejor en futuros trabajos.

\section{LA CONFORMACIÓN DE LA IDENTIDAD NACIONAL SENEGALESA}

Al contrario que en otros países africanos, el proceso de construcción nacional en Senegal parece haber alcanzado un cierto éxito. La identidad nacional senegalesa es aceptada por la mayoría de sus habitantes y el independentismo sólo posee una cierta influencia en la región de Casamance. Asimismo, esta identidad senegalesa se asocia con diversos elementos positivos. Se contrapone, en especial, a la de los países vecinos, cuyos habitantes, más pobres y con un menor dominio del francés, emigran a Senegal, donde a veces se les denomina despectivamente los gnak, "los del matorral", en contraposición a las gentes urbanas y civilizadas. Sigue recordándose también la antigua posición privilegiada del país dentro del conjunto del África Occidental Francesa, como primer territorio colonizado y objeto, por ello, de una atención más prolongada (Versluys, 2010: 239-242). A ello se ha añadido posteriormente el sentimiento de superioridad derivado de la llamada "excepción senegalesa", de desarrollo pacífico y progresivamente democrático, si bien la entrecortada pero progresiva democratización del Sahel desde los años noventa ha aminorado esta diferencia inicial. Tampoco hay que olvidar la contribución a la autoestima colectiva brindada por artistas y deportistas de renombre, ni la deparada por el elevado prestigio de algunos líderes religiosos y por la fama internacional de sus cofradías y sus multitudinarias celebraciones. Esta identidad en positivo exhibe además dos rasgos muy interesantes. Detenta, en primer lugar, un carácter más territorial y estatal que propiamente étnico. Lo que distingue al senegalés es el hecho de ser miembro de una colectividad asentada dentro de unos específicos límites fronterizos. La comunidad nacional queda, así, delimitada más por la común vinculación con un determinado territorio, regido por un determinado Estado, que por una homogeneidad étnica, supuestamente existente con independencia de todo lo anterior.

De hecho, la identidad nacional senegalesa se superpone a una pluralidad de identidades étnicas diferenciadas. Senegal es un país 
multiétnico y además las etnias que lo pueblan son casi todas pluriestatales. Se encuentran distribuidas entre distintos Estados, una situación habitual en el África negra contemporánea. Incluso, en la medida en que estos distintos Estados vertebran ya hasta un cierto punto unas naciones, aunque éstas estén todavía en construcción, se las puede calificar también de etnias plurinacionales. Existe, pues, una clara falta de vinculación con ningún grupo étnico determinado, es decir, con ningún colectivo definido a partir de su lengua y otras características culturales transmitidas de generación en generación, lo cual parece volver más inclusiva esta identidad nacional. Aunque las diferencias inter-étnicas son reconocidas, la convivencia suele ser amigable y los matrimonios mixtos son comunes, al igual que lo es el manejo de lenguas distintas de las del particular grupo étnico al que uno se adscribe (Versluys, 2010: 140-142; Villalón, 1995: 49-52).

Ello no significa, sin embargo, que no exista una cierta identidad compartida basada en una cultura parcialmente común. Esta identidad más inclusiva contribuye a conciliar las distintas identidades étnicas situadas a un nivel más particular. Pero esta identidad y esta cultura comunes se despliegan en varios escalones diferentes. En un plano más general, podemos hablar de una identidad y de una cultura senegambiana, que abarcaría no sólo a Senegal y Gambia, sino también aproximadamente el sur de Mauritania y la mayor parte de Guinea Conakry y Guinea Bissau (Barry, 1988). Podría incluírsela además dentro de otra aún más amplia, la saheliana (Villalón, 1995: 58-60). Ambas sintesis culturales y de identidad, la senegambiana y la saheliana, han quedado conformadas a lo largo de más de un milenio, a través de la interrelación de distintos procesos, como el surgimiento de Estados, la creación de amplias rutas comerciales y la instauración de la esclavitud a gran escala (Meillassoux, 1990). Estos procesos ocasionaron importantes movimientos de población, junto con la difusión de toda una serie de lenguas francas y de códigos de conducta compartidos, capaces de posibilitar un reconocimiento mutuo. La expansión del Islam jugó un papel clave en este último desarrollo, gracias a la difusión no sólo de los elementos de un estilo de vida islámico, de acuerdo a los cánones tradicionales, sino de otros en sí no incluidos dentro del mismo, pero que se le acabaron asociando, tales como el vestido hoy típicamente saheliano o el consumo de nuez de cola. 
$\mathrm{Ni}$ que decir tiene que estas amplias identidades saheliana y senegambiana operan como eficaces medios de diferenciación con respecto a los occidentales, pero también, aunque en menor medida, debido a la común identidad religiosa, frente a los arabo-bereberes del norte. En otro nivel ya más particular, estos procesos de homogenización han propiciado el surgimiento de grandes etnias, por medio de la fusión de distintas colectividades existentes previamente y de la posterior absorción de nuevos colectivos dentro de los grupos dominantes. Es lo que ha ocurrido con los wolof en el caso particular de Senegal. No obstante, la difusión de la cultura, y sobre todo lingüistica, y la difusión de la identidad no se han desarrollado con la misma intensidad. Las lenguas de estos grupos hegemónicos han tendido a convertirse en lenguas para-nacionales, lenguas habladas cotidianamente por quienes no las tienen como lengua materna, ni como fundamento de una nueva identidad étnica, aunque quizá ello sí ocurra con sus hijos (Ngom, 2004; Versluys, 2010: 91-105; Villalón, 1995: 47-58).

La segunda característica central de la identidad senegalesa estriba en su ausencia de vinculación con ningún relato histórico ni con ningún proyecto político especialmente combativos. La débil conexión entre la identidad nacional y cualquier identidad étnica ciertamente resta plausibilidad a cualquier irredentismo territorial dirigido contra otros Estados, en razón de la presunta identidad étnica de sus pobladores. La juventud del Estado senegalés y su ausencia de un nexo privilegiado con ningún Estado precolonial en concreto actúa en el mismo sentido. Tampoco el recuerdo de la lucha independentista ostenta aquí la misma relevancia que en otras antiguas colonias, dado que esta lucha y el período colonial que la precedió resultaron también menos dramáticos. Asimismo, la identidad senegalesa no se vincula con ningún proyecto ideológico en particular. No está ligada a la difusión de ningún credo, ni a la de ningún modelo de sociedad, convirtiendo a los senegaleses en sus portadores privilegiados. No lo está ni siquiera a la difusión del Islam, entre los no musulmanes, ni a la de un mejor Islam, entre los musulmanes tibios. Ciertamente, la laicidad del Estado dificulta esta opción. Sin embargo, no resultaría tan difícil establecer este nexo. Bastaría con reactualizar el recuerdo de las pasadas yihad. Pero esta opción entraría en contradicción con la ya mencionada acomodación mutua entre el Estado y las cofradías sufies y la resultante resignación 
hacia las desviaciones con respecto al ideal postulado, tan poco acorde con un proyecto religioso militante.

En vista de todo ello, la identidad nacional senegalesa se nos presenta como una identidad "amable", sin connotaciones agresivas, descontando los pasados conflictos con los "moros" de Mauritania, que obedecieron a una compleja combinación de factores (Stewart, 1990; Villalón, 1995: 46-47). Parece también una identidad "blanda", en el sentido de no encontrarse vertebrada por ningún elemento de manera excluyente, ni estar tampoco demasiado contrapuesta a otras identidades nacionales. Así parece estar sucediendo, en particular, en lo que atañe a su componente más esencialista. Se dispone de una rica tradición histórica. Pero esta tradición sólo se vincula parcialmente con el Islam, cuya difusión, en extensión y profundidad, ha sido mucho más reciente. En consecuencia, la remisión al Islam y a la identidad musulmana proporciona un sentido de arraigo histórico inferior al que se produce en aquellos otros lugares en donde esta religión se estableció hace ya mil cuatrocientos años. Esta debilidad relativa del componente esencialista, propia de un "país joven", parece estar dejando un mayor espacio para el desarrollo del componente epocalista. De este modo, la visión de Senegal como un país que, aunque con dificultades, se desarrolla y se democratiza ha arraigado claramente. y esta imagen de un país orientado hacia lo moderno se articula muy bien con la de un país musulmán dotado de unas determinadas particularidades, como la coexistencia con la laicidad, una secularidad parcial y una coexistencia también bastante buena con la minoría cristiana (Villalón, 1995: 46).

Merece la pena profundizar un poco más en la posición que se concede a esta minoría cristiana, en torno a un $6 \%$ de la población, en el marco de toda esta construcción nacional. Dejando aparte algunos pequeños núcleos, básicamente de mestizos, afincados en las viejas plazas dedicadas a la trata, la evangelización comenzó durante el período colonial y discurrió entre aquellas poblaciones no afectadas por la expansión final del Islam. La diferencia resulta patente con respecto a varios países de Oriente Próximo, en donde la minoría cristiana goza de un arraigo de dos mil años, anterior a la llegada del Islam. En estos lugares las relaciones inter-confesionales se encuentran fuertemente condicionadas por toda una historia previa, conflictiva en ciertos períodos. En el curso de esta compleja historia en común han 
cristalizado unos estereotipos y unas pautas de interacción difíciles hoy de superar. Asimismo, el hecho de que esta interacción haya estado regida durante siglos por las normas de la mayoría, es decir, por el derecho islámico, la ha imbuido de una naturaleza frecuentemente discriminatoria.

Ninguna de ambas cosas ha ocurrido en Senegal, en donde tanto la islamización de la mayoría como la difusión del cristianismo más allá de las plazas coloniales han sido dos fenómenos recientes y simultáneos y en donde ambos han estado sujetos desde entonces a las regulaciones establecidas por unas autoridades aconfesionales. A estos dos primeros factores se han añadido otros dos, también de gran importancia. Los cristianos son muy minoritarios en Senegal y, por lo tanto, resulta difícil percibirlos como una amenaza. Asimismo, las fronteras interconfesionales no se superponen con las existentes entre etnias rivales. La diferencia en ambos aspectos con respecto a otros paises de la región, especialmente Nigeria, resulta manifiesta. Naturalmente, si los grupos que dentro de Senegal abogan por la islamización del Estado adquiriesen una mayor influencia, la convivencia interreligiosa podría empeorar. Podría ocurrir entonces, como en el caso clásico de Egipto (Kepel, 1988: 252-255), que los cristianos fuesen tomados como chivo expiatorio de los graves problemas sociales, como un enemigo frente al cual fortalecer la comunidad en construcción de los creyentes revividos o como un pretexto para desafiar a un régimen que se desea cambiar, y que se empeña en tratar como iguales a quienes merecen ser discriminados. De hecho, en alguna ocasión pasada pequeños grupos de musulmanes han agredido a los cristianos y a sus lugares de culto, les han presionado para convertirse al Islam y han tratado de impedirles la celebración pública de sus ritos religiosos (Coulon, 1981: 269).

\section{UN PRAGMATISMO AMABLE}

Sin embargo, un conflicto inter-religioso en gran escala parece muy poco probable actualmente. La razón principal estriba en el tipo de Islam que se ha desarrollado en el país. En concreto, el proceso de acomodación mutua entre Estado y cofradías parece haber propiciado entre una gran parte de la población una particular orientación vital, una búsqueda prioritaria de unos determinados objetivos en la vida, (Castien, 2008: 44-45). Vamos a denominarla, de un modo ciertamente aproximativo, un pragmatismo amable. Se trata de una disposición a 
adaptarse al mundo real con todas sus complejidades. Partiendo de ella, resulta más fácil convivir con personas con ideologías y estilos de vida diferentes. Prima ante todo el interés por disfrutar de la existencia cotidiana, llevándose bien con el otro y sabiendo apreciar sus rasgos positivos. Semejante orientación contrasta fuertemente con la propia de cualquier fundamentalismo ideológico, caracterizada ésta por el afán de organizar la realidad sobre la base de unos pocos principios doctrinales, eliminando cualquier obstáculo que se oponga a este objetivo (Hoffer, 2009). Frente a la ansiada imposición de unos presuntos mandatos divinos, defendida por los musulmanes más rigoristas, el pragmatismo amable supone una orientación más mundana, que trata de conciliarlos con la búsqueda de la felicidad en el plano terrenal. Ello implica, aunque sea de manera implícita, una cierta secularización, una autonomización normativa con respecto a la religión.

Naturalmente, esta orientación vital ha sido muy frecuente entre los musulmanes a lo largo de la historia. Adolece, sin embargo, del problema de que no se encuentra siempre respaldada por un sistema de creencias bien establecido, dado que las versiones oficiales mayoritarias del Islam han sido históricamente mucho más rigoristas. De ahí entonces su carácter precario (Charfi, 2001: 23 y 242-244). En el caso de que se empiece a prestar más atención al propio sistema de creencias profesado, es probable que se rechace la tibieza que conlleva esta orientación y se opte por otra de índole más fundamentalista. Puede que ocurra así, desde luego, en momentos de crisis, cuando se buscan certidumbres que deparen un mayor sentimiento de seguridad (Hoffer, 2009). Pero puede también que resulte de la adopción de una orientación más intelectualista, más preocupada por la coherencia entre postulados abstractos. Así puede acaecer en el curso de un proceso de modernización, cuando se incrementa el nivel de formación de las personas y su curiosidad por las cuestiones teóricas (Geertz, 1987: 152155). Aunque pueda parecer paradójico, el desarrollo del fundamentalismo islámico podría resultar ser entonces una consecuencia, más o menos indirecta, de la modernización. Esta tendencia puede reforzarse si además, como señalamos en el primer apartado, aparecen unas mayores necesidades de integración social, que una ideología y una identidad simples y globales, como las proporcionadas por los fundamentalismos, pueden quizá satisfacer. Es 
esto lo que parece estar ocurriendo hoy en día en bastantes regiones del mundo islámico (Roy, 2003: 83-105).

En lo que respecta en concreto al caso senegalés, los movimientos islamistas y salafistas parecen beneficiarse asimismo del rechazo a las formas de sumisión tradicional al sheij, en consonancia quizá con el desarrollo de un individualismo de tipo moderno, y de un afán por profesar un Islam más acorde con sus versiones internacionalmente más difundidas (Augis, 2008: 227). Pero esta postura es denunciada por otros senegaleses como una mera imitación del Islam "de los árabes", ajeno a la idiosincrasia local. La vieja tesis del "Islam negro" resulta, así, parcialmente recuperada. Por otra parte, las propias cofradías han demostrado una vez más su versatilidad, apropiándose de ciertas aportaciones de esta otra versión del Islam, como sus métodos docentes (Costa, 2009: 50-57; Ware, 2008: 33-36). También han surgido auténticos movimientos híbridos, liderados por miembros más jóvenes de las familias sufies tradicionales (Samson, 2008; Seck, 2010: 68-90).

En definitiva, el pragmatismo amable senegalés no está exento de ciertas amenazas. Sin embargo, creemos que existen algunos factores que lo están protegiendo. En primer lugar, el propio hecho de que las relaciones inter-confesionales sean razonablemente buenas elimina una importante fuente de agravios entre comunidades, capaz de empujar a ciertos sectores, de cualquiera de las dos confesiones implicadas, hacia una concepción excluyente y agresiva de su identidad religiosa, la cual podría conectar luego fácilmente con una orientación general de corte fundamentalista. El pragmatismo amable así potenciado favorece, a su vez, una buena convivencia interreligiosa, conformándose con ello un auténtico círculo virtuoso. El segundo factor a tener en cuenta radica en la propia consolidación de una cultura democrática, propicia para el pacto entre personas con distintos puntos de vista. Incluso, las prácticas clientelistas, muy arraigadas en la sociedad senegalesa, pueden estar operando en este mismo sentido, al otorgar primacía a los acuerdos para el reparto de prebendas dentro de redes de contactos muy complejas, en donde participan gentes con afiliaciones ideológicas muy distintas.

Pero a estos dos factores externos, habría que añadir otros de carácter más interno, más vinculados ya con determinadas particularidades del Islam senegalés. Es lo que puede estar ocurriendo con el predominio del sufismo. Si bien históricamente el sufismo se ha podido combinar, 
especialmente en el Sahel, con una postura rigorista en lo normativo y con un proyecto político teocrático, la prioridad que otorga a la experiencia mística puede, en ocasiones, relegar las cuestiones jurídicas y doctrinales a un plano más secundario. Asimismo, el énfasis otorgado a la relación con el sheij como instrumento para alcanzar la salvación ultraterrena, pero también para alcanzar el bienestar terrenal, puede estar favoreciendo igualmente un cierto desinterés por esas mismas cuestiones, consideradas de utilidad secundaria en comparación con los beneficios reportados por los actos de devoción hacia el maestro. Por otra parte, la insistencia reiterada en la experiencia mística y en las acciones rituales, como acciones efectuadas en general tan sólo en momentos y ámbitos circunscritos, podría estar dejando, por así decir, un espacio libre para el desarrollo del ya referido pragmatismo amable. Tendría lugar, de este modo también, una secularización parcial e implícita. Naturalmente, dentro de las específicas esferas de experiencia en donde se desarrollan estas prácticas rituales, estas vivencias místicas y estos vínculos personales, esta particular actitud vital encontraría una menor cabida. Se abrigaría, por el contrario, una actitud más comprometida con los propios postulados y más hostil hacia quienes los desafiaran. No está de más recordar a este respecto que los ocasionales incidentes violentos entre partidarios de distintos marabut, o las agresiones contra quienes han osado cuestionar las dotes místicas o las conductas más profanas de alguno de estos líderes, han sido una constante en el país desde hace generaciones (Seck, 2010).

Con todo, quizá el refuerzo más poderoso que esté encontrando este pragmatismo amable estribe en la asociación realizada por ciertos informantes nuestros entre esta orientación y su específica identidad musulmana. Descrito como moderado y tolerante en términos globales, el Islam senegalés resulta para ellos potencialmente más compatible con ese mínimo de secularidad y de autonomía individual propio del mundo moderno. Esta misma caracterización puede aplicarse también al cristianismo del país. Estos rasgos particulares de las identidades religiosas locales son también atribuidos a la propia identidad nacional senegalesa. Ello incrementa su valoración positiva, sobre todo en comparación con las identidades nacionales de los pueblos vecinos. Esta especificidad senegalesa así reforzada resulta asimismo enriquecida a través de una concepción global del pueblo senegalés como un pueblo "con fe". Semejante fe es definida en abstracto, abarcando tanto a 
musulmanes como a cristianos. No supone por tanto, la adhesión a unas doctrinas y unas prácticas concretas, sino a una orientación religiosa genérica (Castien, 2009: 48-54), entendida como una virtud personal general. Implica la creencia en algo superior, con cuyo concurso será más fácil alcanzar las propias metas personales. Esta visión optimista de la existencia ayudaría a afrontar con éxito unas condiciones de vida a menudo difíciles. De ahí que pueda ser presentada incluso como un agente de desarrollo, capaz de contribuir a una futura igualación con los países más ricos. Se hace posible también equiparar ahora a musulmanes y cristianos como gentes de fe, conformándose, de este modo, una identidad religiosa más inclusiva, lo que aminora la potencial contradicción entre estas identidades religiosas particulares y la identidad nacional senegalesa.

En síntesis, el Islam senegalés ha quedado conformado a través de una serie de bifurcaciones históricas, propiciadas por distintos acontecimientos particulares. El Islam híbrido originario, vinculado al sistema aristocrático, fue reemplazado por otro más "ortodoxo" promovido por las cofradías sufíes, cuando este sistema aristocrático se derrumbó, como consecuencia, en parte, de la decadencia de la trata esclavista y del ulterior avance colonial. Pero el proyecto teocrático marabútico subsiguiente abortó ante la necesidad de acomodarse al Estado laico introducido por la colonización. La acomodación mutua entre Estado y cofradías ha derivado luego en una auténtica contención recíproca y en un cierto reparto de esferas de influencia. La democratización resultante ha potenciado, a su vez, una versión de las identidades religiosa y nacional más compatible con las exigencias de la modernización y ha restado atractivo al proyecto islamista. Pero todos estos desarrollos podrían verse revertidos en el futuro. Bastaría con alguna pequeña alteración en cualquiera de los factores implicados para que surgiese una nueva configuración muy diferente de la actual. El Estado podría volverse entonces más autoritario, el Islam político incrementar su influencia o las relaciones inter-confesionales deteriorarse. Es preciso evitar, pues, cualquier tentación esencialista, así como cualquier optimismo excesivo.

\section{BibLiOgRAFÍA}

Augis, E. (2008). Jambar or Jumbax-out. How Sunnite Women Negotiate Power and Belief in Orthodox Islamic Feminity. In M. Diouf \& M. 
Leichtman (Eds), New Perspectives on Islam in Senegal. Conversion, Migration, Wealth, Power and Feminity (pp. 91-110). Nueva York: Palgrave Macmillan.

Ayubi, N. (1998). Política y sociedad en Oriente Próximo. La hipertrofia del Estado árabe. Barcelona: Bellaterra.

Babou, C. (2007). Fighting the Greater Jihad. Amadu Bamba and the Founding of the Muridiyya of Senegal, 1853-1913. Ohio: Ohio University Press.

Barry, B. (1988). La Sénégambie du Xveme au XIXeme siècle. Traite négriére, Islam, conquête coloniale. París: L'Harmattan.

Bathily, A. (1989). Les portes de l'or. Le royaume de Galam (Sénégal) de l'ére musulmane au temps des nègriers. París: L'Harmattan.

Burgat, F. (1996). El islamismo cara a cara. Barcelona: Bellaterra.

Carré, O. (1996). El Islam laico. ¿Un retorno de la Gran Tradición? Barcelona: Bellaterra.

Castien, J. (2008). Georg Lukács y la naturaleza del hecho religioso. Ilú. Revista de ciencias de las religiones, 13, 35-54.

Charfi, M. (2001). Islam y libertad. El malentendido histórico. Barcelona: Almed.

Copans, J. (1989). Les marabouts de l'arachide. La confrérie mouride et les paysans de Sénégal. París: L'Harmattan.

Costa, E. (2009). Cofradías musulmanas y movimiento Dawa: dos concepciones del islam en África occidental. In F. Iniesta (Ed.). El islam del África Negra (pp. 39-60). Barcelona: Bellaterra.

Coulon, C. (1981). Le marabout et le prince. Islam et pouvoir au Sénégal. Burdeos: Institut D'Études Politiques de Bordeaux.

Coulon, C. (2009). Las dinámicas del Islam en el África negra en el umbral del siglo XXI: entre lo local y lo global, el islam como derivación. In $\mathrm{F}$. Iniesta (Ed.). El islam del África Negra (pp.61-80). Barcelona: Bellaterra.

Diop, A. (1981). La société wolof, Tradition et changement, Les systemes d'inegalité et de domination. París: Karthala.

Elias, N. (1990). La sociedad de los individuos. Ensayos. Barcelona: Península.

El Ayadi, M., Rachik, H. y Tozt, M. (2007). L'Islam au quotidien. Enquête sur les valeurs et les pratiques religieuses au Maroc. Casablanca: Éditions Prologues. 
Geertz, C. (1971). Islam observed. Chicago: The University of Chicago Press.

Geertz C. (1987). La interpretación de las culturas. Barcelona: Gedisa.

Gellner, E. (1989). Naciones y nacionalismo. Madrid: Alianza Editorial.

Giddens, A. (1995). Modernidad e identidad del yo. El yo y la sociedad en la edad contemporánea. Barcelona: Península.

Hastings, A. (2002). La construcción de las nacionalidades. Cambridge: Cambridge University Press.

Hoffer, E. (2009). El verdadero creyente. Sobre el fanatismo y los movimientos sociales. Madrid: Tecnos.

Kepel, G. (1988). Faraón y El Profeta. Barcelona: Muchnik.

Loimeier, R. (2008). Dialectics of Religion and Politics in Senegal. In M. Diouf \& M. Leichtman (Eds). New Perspectives on Islam in Senegal. Conversion, Migration, Wealth, Power and Feminity (pp. 237-256). Nueva York: Palgrave Macmillan

Magassouba, M. (1985). L'Islam au Sénégal: demain les mollahs? La "question" musulmane et es partis politiques au Sénégal de 1946 à nos jours. París: Karthala.

Meillassoux, C. (1990). Antropología de la esclavitud. El vientre de hierro y de dinero. Madrid: Siglo XXI.

Ndao, I. (2003). Sénégal: histoire des cônquets démocratiques: essai. Dakar: Nouvelles editions africaines du Sénégal.

Ngom, F. (2004). Ethnic identity and linguistic hibridization in Senegal. International Journal of the Sociology of Language, 170, 95-111.

Pascon, P. (1984). Le Maison d'lligh et I'histoire social de Tazerwalt. Rabat: Société Marocain des Editeurs Réunis.

Robinson, D. (1988). La guerre sainte d'al-Hajj Umar. Le Soudan occidental au milieu du XIX éme siècle. París: Karthala.

Robinson, D. (2000). Paths of Accommodation. Muslim societies and French Colonial Authorities in Senegal and Mauritania, 1880-1920. Ohio: Ohio University Press.

Roy, O. (2003). El Islam mundializado. Los musulmanes en la era de la globalización. Barcelona: Bellaterra.

Samson, F. (2008). Islam, Protest and Citinzen Mobilization. Neo-Sufi Movements. In M. Diouf \& M. Leichtman (Eds). New Perspectives on Islam in Senegal. Conversion, Migration, Wealth, Power and Feminity (pp. 257-272). Nueva York: Palgrave Macmillan. 
Searing, J. (2008). The Great Jihad and Conversion: Serer Interpretation of Sufi Islam in Senegal. In M. Diouf \& M. Leichtman (Eds). New Perspectives on Islam in Senegal. Conversion, Migration, Wealth, Power and Feminity (pp. 91-110). Nueva York: Palgrave Macmillan.

Seck, A. (2010). La question musulmane au Senegal. Essai d'anthropologie d'une nouvelle modernité. París: Karthala.

Seck, A. (2005). Sénégal. Émergence d'une démocratie moderne 1945-2005. París: Karthala.

Seesemann, R. (2011). The Divine Flood. Ibrahim Niasse and the Roots of a Twentieth-Century Sufi Revival. Oxford: Oxford University Press.

Stewart C. (1973). Islam and social order in Mauritania. A Case Study from the Nineteenth Century. Oxford: Clarendon Press.

Stewart C. (1990). Une interpretation du conflit sénégalo-mauritanien. Revue du Monde Musulman et de la Mediterranée, 54, 161-170.

Vassiliev, A. (2000). The History of Saudi Arabia. Londres: Saqi Books.

Versluys, E. (2010). Langues et identities au Senegal. París: L'Harmattan.

Villalón, L. (1995). Islamic Society and State Power in Senegal. Disciples and citizens in Fatick. Cambridge: Cambridge University Press.

Ware, R. (2008). The Longue Durée of Quran Scholing, Society and State in Senegambia. In M. Diouf \& M. Leichtman (Eds). New Perspectives on Islam in Senegal. Conversion, Migration, Wealth, Power and Feminity (pp. 21-50). Nueva York: Palgrave Macmillan

Zarcone, T. (2005). El Islam en la Turquía actual. Barcelona: Bellaterra. 